\title{
TINGKAT KESIAPAN MASYARAKAT LOKAL TERHADAP PENGEMBANGAN COMMUNITY BASED TOURISM (CBT) DI KABUPATEN SAMOSIR
}

\author{
Sugiharto' ${ }^{1}$, Fitra Delita1, Tumiar Sidauruk ${ }^{1}$ \\ 1Jurusan Pendidikan Geografi Fakultas Ilmu Sosial Universitas Negeri Medan \\ Jl. Willem Iskandar Psr V Medan Estate Medan, 20211 Indonesia \\ email : fitradelita@unimed.ac.id
}

\begin{abstract}
Abstrak
Kabupaten Samosir memiliki potensi besar dalam industri pariwisata. Pengembangan sektor pariwisata di Kabupaten Samosir tentunya akan berdampak pada kehidupan masyarakat lokal terutama dibidang ekonomi, budaya (culture), sosial masyarakat dan lingkungan. Tujuan utama penelitian ini yaitu menganalisis tingkat kesiapan masyarakat lokal terhadap pengembangan pariwisata berbasis masyarakat (CBT) di Kabupaten Samosir. Pengukuran kesiapan masyarakat dengan skala likert yang terbagi atas aspek perencanaan, pengelolaan dan evaluasi pengembangan wisata berbasis masyarakat. Kemudian data dianalisis menggunakan SPSS $v .20$ dengan alat analisis One-way ANOVA. Hasil penelitian menunjukkan terdapat perbedaan tingkat kesiapan masyarakat pada aspek perencanaan, pengelolaan dan evaluasi pengembangan wisata berbasis masyarakat di Kabupaten Samosir. Faktor utama yang mempengaruhi tingkat kesiapan masyarakat lokal dalam pengembangan CBT di Kabupaten Samosir yaitu pendidikan dan umur.
\end{abstract}

Kata kunci: kesiapan masyarakat, CBT, Kabupaten Samosir

\section{PENDAHULUAN}

Sektor pariwisata menjadi sektor penyumbang devisa terbesar di Indonesia setelah migas. Pada tahun 2015 kunjungan wisatawan mancanegara memberikan sumbangsih pada devisa sebanyak Rp. 144 triliun. Bahkan pada tahun 2020, Kementerian Pariwisata memprediksi industri pariwisata Indonesia akan menghasilkan devisa yang paling tinggi (LAK Kemenpar, 2015). Apalagi dengan branding "Wonderful Indonesia" yang mampu mengangkat prestasi pariwisata seperti: UNWTO Award 2015, ASEANTA Award 2015, World Halal Destination 2015.

Danau Toba menjadi bagian
destinasi wisata dalam branding
"Wonderful Indonesia". Danau ini
mengelilingi Pulau Samosir yang secara
adiministratif termasuk dalam wilayah
Kabupaten Samosir. Kabupaten Samosir
memiliki sekitar 75 objek/daya tarik

wisata yang tersebar di 9 kecamatan (BPS Kabupaten Samosir, 2016). Strategi pengembangan objek wisata yang dapat dilakukan antara lain dengan membangun sarana prasarana seperti akses jalan, alat angkut dan sarana akomodasi, mengelola dan mempromosikan atraksi wisata dan mengembangkan produk wisata, serta menjamin keterlibatan dan manfaat bagi masyarakat lokal (Delita, et al., 2017).

Pembangunan industri pariwisata Kabupaten Samosir tentunya akan berhasil jika masyarakat dilibatkan dalam pengambilan keputusan, pengelolaan dan memperoleh manfaat dari pariwisata tersebut. Masyarakat lokal harus dilibatkan sehingga mereka mendukung program pariwisata di daerahnya. Strategi yang dapat dijalankan yaitu melalui pariwisata berbasis masyarakat/ Community Based Tourism (CBT). Pariwisata berbasis masyarakat merupakan aktivitas interaktif antara turis 
dan masyarakat lokal yang dapat meningkatkan ekonomi dan keuntungan bagi masyarakat lokal (Baryamujura, 2015). CBT dapat meningkatkan keberlajutan sosial dengan memberdayakan masyarakat lokal untuk mengelola SDA yang mereka miliki, menyediakan peluang kerja dan membangun kapasitas serta pelestarian budayanya (Asker et al., 2010). CBT merupakan strategi pariwisata yang mengutamakan keberlangsungan lingkungan, sosial dan budaya. CBT dapat berfungsi sebagai sarana/media membangun komunitas dan konservasi lingkungan sesuai dengan pembangunan pariwisata berkesinambungan (Suansri, 2003). Terdapat beberapa prinsip utama strategi pengembangan kepariwisataan yang berbasis pada masyarakat lokal (Sunaryo, 2013), yaitu : mengikutsertakan anggota masyarakat dalam pengambilan keputusan, manfaat aktivitas kepariwisataan yang diperoleh masyarakat lokal, pendidikan/pelatihan terkait pariwisata bagi masyarakat lokal.

Penelitian Brida et al. (2011) menemukan kesiapan masyarakat untuk aktif terlibat dibutuhkan dalam menentukan kebijakan pengembangan pariwisata. Keterlibatan masyarakat lokal pada pengembangan daerah tujuan/ destinasi wisata sangat penting, salah satunya dalam pembuatan keputusan (Zadel et al., 2014). Berdasarkan uraian tersebut, maka tujuan utama yang menjadi fokus dalam penelitian ini yaitu menganalisis tingkat kesiapan masyarakat terhadap pengembangan pariwisata berbasis masyarakat masyarakat/ Community Based Tourism (CBT) di Kabupaten Samosir.

\section{METODE PENELITIAN}

Sampel penelitian ini ditetapkan sebanyak 450 orang yang berada di 9 kecamatan (50 orang/kecamatan). Teknik pengambilan sampel yang dilakukan adalah purposive sampling dengan pertimbangan pada wilayah ini terdapat banyak masyarakat yang tinggal di sekitar objek wisata.
Pengumpulan data tingkat kesiapan masyarakat dilakukan menggunakan kuesioner yang terdiri atas variabel perencanaan, pengelolaan dan evaluasi pengembangan wisata berbasis masyarakat. Tingkat kesiapan masyarakat diukur dengan skala likert dengan scoring terdiri atas 5 kategori yaitu Sangat Siap $(\mathrm{SS})=5$; $\operatorname{Siap}(\mathrm{S})=4$; Ragu-Ragu $(\mathrm{R})=3$; Tidak Siap $(\mathrm{TS})=2$; dan Sangat Tidak Siap $(\mathrm{STS})=1$. Pengujian validitas dan reliabilitas instrumen dilakukan untuk mencegah bias dan memastikan konten/ item pernyataan mendukung tercapainya tujuan penelitian. Uji reliabilitas menggunakan Cronbach's alpha kemudian data disusun, ditabulasi dan dianalisis menggunakan SPSS 2.0.

\section{HASIL DAN PEMBAHASAN \\ Gambaran Umum Lokasi Penelitian}

Secara astronomis Kabupaten Samosir terletak di antara $2^{\circ} 21^{\prime}-20^{\circ} 49^{\prime} \mathrm{LU}$ dan $98^{\circ} 24^{\prime}$ - $99^{\circ} 01^{\prime} \mathrm{BT}$ pada ketinggian wilayah antara 904 - 2.157 mdpl. Luas wilayahnya $\pm 2.069,05 \mathrm{~km}^{2}$, yang terbagi atas daratan dan danau. Luas daratan sekitar $1.444,3 \mathrm{~km}^{2}$ dan wilayah danau seluas $624,8 \mathrm{~km}^{2}$. Jumlah penduduk Kabupaten Samosir pada tahun 2015 (hasil proyeksi penduduk) adalah 123.789 jiwa, yang terdiri atas 61.406 laki-laki $(49,61 \%)$ dan 62.383 perempuan $(50,39 \%)$, dengan rasio jenis kelamin 98,43 dan angka kepadatan penduduk 85,71 jiwa/ $\mathrm{km}^{2}$.

Menurut persebaran penduduk tiap kecamatan, jumlah penduduk terbanyak di Kecamatan Pangururan, yaitu 30.468 jiwa (24,61\%), dengan kepadatan penduduk 250,91 jiwa/ $\mathrm{km}^{2}$. Sedangkan jumlah penduduk yang paling sedikit berada di Kecamatan Sitiotio yaitu 7.341 jiwa $(5,93 \%)$, dengan kepadatan penduduk 144,62 jiwa/ $\mathrm{km}^{2}$. Kecamatan dengan kepadatan penduduk terendah yaitu Kecamatan Harian. Padahal Kecamatan Harian memiliki wilayah yang paling luas, yaitu $560,45 \mathrm{~km}^{2}$, tetapi hanya didiami oleh penduduk sebanyak 8.114 jiwa (6,55\%) dengan rata-rata 14,48 jiwa/ $\mathrm{km}^{2}$. Karena sebagian besar penggunaan 
lahan di Kecamatan Harian adalah areal hutan produksi, hutan lindung dan juga areal pertanian. Lokasi penelitian ini adalah seluruh Kecamatan yang berada di Kabupaten Samosir yaitu Kecamatan Simanindo, Kecamatan Sianjur Mula-mula,
Kecamatan Pangururan, Kecamatan Harian, Kecamatan Ronggur Nihuta, Kecamatan Onanrunggu, Kecamatan Nainggolan, Kecamatan Palipi, dan Kecamatan Sitiotio (Gambar 1).

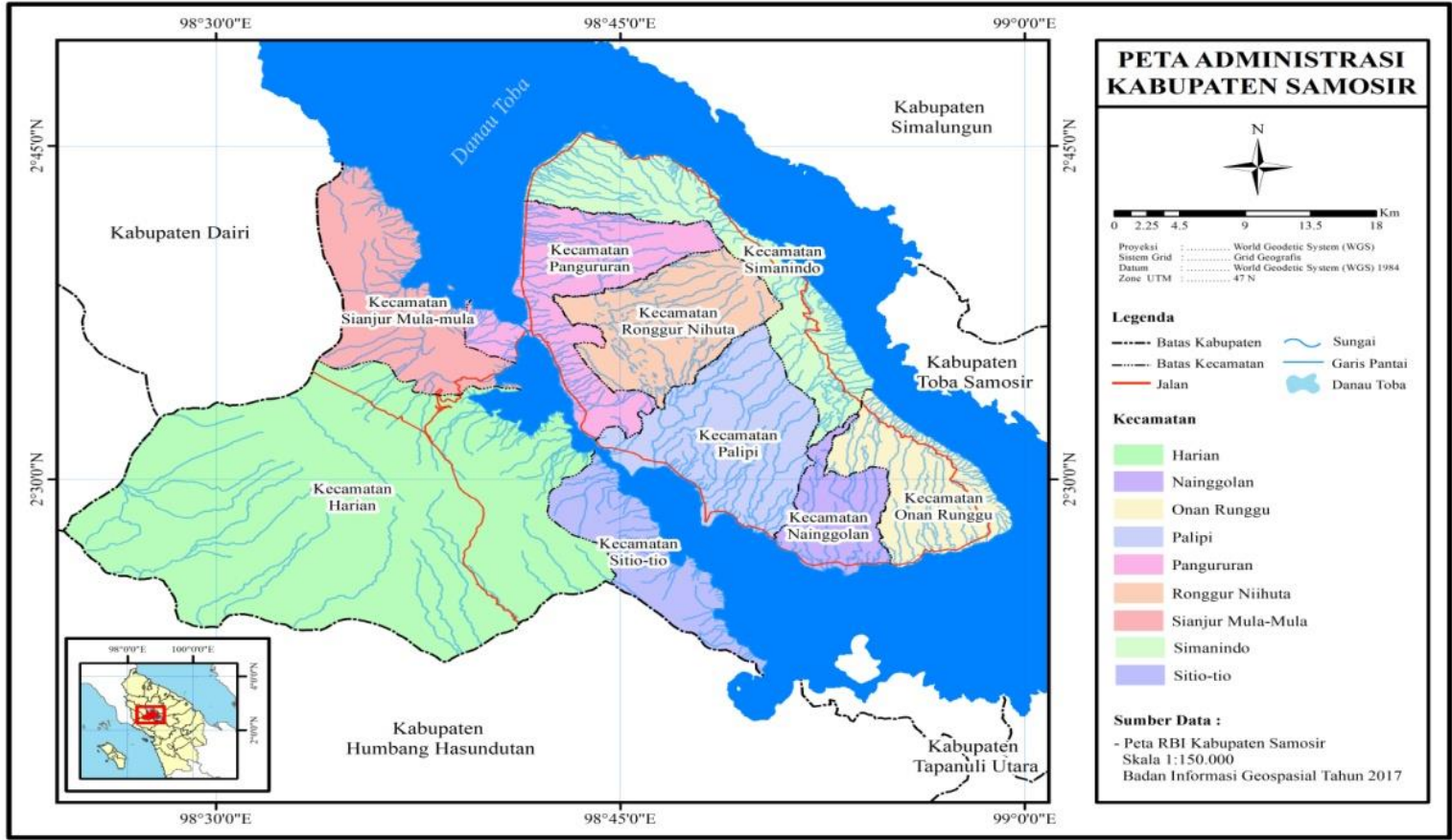

Gambar 1. Peta administrasi Kabupaten Samosir

Kesiapan Masyarakat Terhadap CBT

Kesiapan masyarakat Kabupaten Samosir dalam pengembangan Community Based Tourism (CBT) terbagi atas 3 aspek yaitu perencanaan, pengelolaan dan evaluasi pengembangan wisata. Pada aspek perencanaan masih rendah pada kriteria penyusunan anggaran $(2,15)$ dan penyusunan master plan $(2,38)$ sedangkan pada kriteria perencanaan atraksi wisata $(4,12)$ dan perencanaan SDA $(4,00)$ tergolong tinggi. Pada aspek pengelolaan rata-rata kriteria sudah tinggi. Pada aspek evaluasi, kriteria evaluasi anggaran dan SDM termasuk pada kategori rendah. Perhatikan Tabel 1 berikut ini :

Tabel 1. Tingkat Kesiapan Masyarakat Terhadap Pengembangan CBT

\begin{tabular}{clcc}
\hline Variabel & \multicolumn{1}{c}{ Kriteria } & Mean & SD \\
\hline Perencanaan & Penyusunan master plan pariwisata & 2,38 & 1,31 \\
& Penyusunan anggaran & 2,15 & 0,36 \\
& Penyusunan perencanaan SDM & 3,63 & 1,24 \\
& Penyusunan perencanaan SDA & 4,00 & 1,33 \\
& Penyusunan perencanaan aksesibilitas & 2,88 & 0,50 \\
& Penyusunan perencanaan atraksi wisata & 4,12 & 0,69 \\
& Penyusunan perencanaan amenitas wisata & 3,40 & 0,55 \\
\hline \multirow{2}{*}{ Pengelolaan } & Pengelolaan anggaran & 3,83 & 0,50 \\
& Pengelolaan SDM & 3,11 & 1,19 \\
& Pengelolaan SDA & 3,98 & 0,66 \\
\hline
\end{tabular}




\begin{tabular}{llcc}
\hline Variabel & \multicolumn{1}{c}{ Kriteria } & Mean & SD \\
\hline & Pengelolaan aksesibilitas & 2,82 & 1,18 \\
& Pengelolaan atraksi wisata & 3,48 & 1,34 \\
& Pengelolaan amenitas wisata & 3,09 & 1,20 \\
\hline \multirow{2}{*}{ Evaluasi } & Evaluasi anggaran & 2,13 & 0,94 \\
& Evaluasi SDM & 2,35 & 1,34 \\
& Evaluasi SDA & 3,40 & 0,55 \\
& Evaluasi aksesibilitas & 3,41 & 1,61 \\
& Evaluasi atraksi wisata & 2,52 & 1,34 \\
& Evaluasi amenitas wisata & 2,99 & 1,12 \\
\hline
\end{tabular}

Sumber: Hasil Penelitian, 2018

Berdasarkan hasil penelitian tersebut, ternyata kesiapan masyarakat Kabupaten Samosir masih rendah pada aspek perencanaan dan evaluasi pengembangan wisata. Hal ini dikarenakan pengembangan pariwisata yang berlangsung selama ini masih bersifat parsial, dikuasai pihak tertentu seperti swasta dan kurangnya keterlibatan masyarakat, sehingga pengetahuan masyarakat pada aspek tersebut masih terbatas. Dengan demikian perlu adanya pendidikan kepariwisataan bagi masyarakat. Sebab, pengembangan industri pariwisata akan berpengaruh pada kehidupan masyarakat lokal baik perubahan ekonomi, budaya, kehidupan sosial maupun perubahan lingkungan. Hal ini sejalan dengan teori yang dikemukakan Murphy dalam Muallisin (2007) bahwa pariwisata berbasis masyarakat (CBT) erat kaitannya dengan dampak pariwisata pada masyarakat lokal dan SD lingkungan (environmental resources).

\section{Kesiapan Masyarakat Terhadap CBT Berdasarkan Umur}

Hasil analisis statistik dengan alat uji ANOVA satu jalur (one-way) menunjukkan dengan variasi umur, nilai $\mathrm{dF}$ hitung $(3,196)>\mathrm{F}$ tabel $(2,60, \alpha=0.05)$; sig $(0,000$ dan 0,008) $<0,05$ dari aspek perencanaan dan pengelolaan. Dengan demikian berdasarkan umur terdapat perbedaan kesiapan yang signifikan pada aspek perencanaan dan pengelolaan pariwisata berbasis masyarakat. Pada aspek evaluasi pengembangan pariwisata tidak terdapat perbedaan yang signifikan dari kelompok umur karena nilai sig 0,697 $>\mathrm{a}=0,05$. Rata-Rata (mean) tertinggi terdapat pada umur 18-35 dan >35-50 yang menandakan bahwa pada usia ini kesiapan masyarakat untuk terlibat dalam (CBT) tergolong tinggi. Hal terlihat pada Tabel 2 berikut:

Tabel 2. Kesiapan Masyarakat Terhadap CBT Berdasarkan Umur

\begin{tabular}{lccccccc}
\hline \multirow{1}{*}{ Aspek } & \multicolumn{4}{c}{ Mean } & & ANOVA \\
\cline { 2 - 4 } \cline { 8 - 9 } & $<$ & & & $>$ & & \\
& 18 & $18-35$ & $35-50$ & 50 & & F Value & p Value \\
\hline Perencanaan & 2,87 & 2,97 & 3,11 & 2,47 & & 6,746 & .000 \\
Pengelolaan & 3,28 & 3,64 & 3,56 & 3,51 & & 4,014 & .008 \\
Evaluasi & 2,44 & 2,56 & 2,63 & 2,21 & & 0,481 & .697 \\
\hline
\end{tabular}

Df $=3,196 ; F$ Value $=2.60$ and $p$ Value $=0.05$

Sumber: Analisis Data, 2018

\section{Kesiapan Masyarakat Terhadap CBT Berdasarkan Jenis Kelamin}

Berdasarkan hasil analisis statistik dengan ANOVA satu jalur (one-way) menunjukkan pada kategori jenis kelamin, 
nilai $\mathrm{dF}$ hitung $(1,198<\mathrm{F}$ tabel $(3,84, \mathrm{a}=$ 0.05) untuk aspek perencanaan dan pengelolaan dengan sig (0.088 and 0.093) > 0,05. Pada aspek evaluasi, $\mathrm{p}$-value (Sig. $=$ $0.003)<a=0.05$. Dengan demikian dari kategori jenis kelamin tidak terdapat perbedaan kesiapan yang signifikan pada aspek perencanaan dan pengelolaan namun pada aspek evaluasi terdapat perbedaan kesiapan yang signifikan. Pada aspek evaluasi, nilai mean laki-laki lebih tinggi daripada perempuan artinya pada aspek evaluasi, kesiapan laki-laki lebih tinggi. Hal ini terlihat pada Tabel 3 berikut :

Tabel 3. Kesiapan Masyarakat Terhadap CBT Berdasarkan Jenis

Kelamin

\begin{tabular}{lccccc}
\hline \multirow{2}{*}{ Aspek } & \multicolumn{2}{c}{ Mean } & & \multicolumn{2}{c}{ ANOVA } \\
\cline { 2 - 3 } \cline { 5 - 6 } & $\begin{array}{c}\text { Laki- } \\
\text { laki }\end{array}$ & Perempuan & & F Value & p Value \\
\hline Perencanaan & 2,92 & 2,98 & & 2,945 & .088 \\
Pengelolaan & 3,49 & 3,42 & & 2,847 & .093 \\
Evaluasi & 2,48 & 2,37 & & 8,843 & .003 \\
\hline
\end{tabular}

$\mathrm{Df}=1,198 ; \mathrm{F}$ Value $=3.84$ and $\mathrm{p}$ Value $=0.05$

Sumber : Analisis Data, 2018

\section{Kesiapan Masyarakat Terhadap CBT Berdasarkan Pendidikan}

Hasil analisis statistik dengan ANOVA ANOVA satu jalur menunjukkan dengan kategori pendidikan, nilai $\mathrm{dF}$ hitung $(4,195)>\mathrm{F}$ tabel $(2,37, \mathrm{a}=0.05)$; sig 0,427 >0,05 dari aspek perencanaan kemudian sig 0,022 dan 0,000 < 0,05 pada aspek pengelolaan dan evaluasi pengembangan pariwisata. Dengan demikian pada kategori pendidikan terdapat perbedaan kesiapan yang signifikan pada aspek pengelolaan dan evaluasi pariwisata berbasis masyarakat.

Pada aspek perencanaan tidak terdapat perbedaan yang signifikan karena nilai sig 0,427>a=0,05. Rata-Rata (mean) paling tinggi berada pada masyarakat yang menempuh pendidikan tinggi (Diploma, S1 dan S2). Artinya kelompok masyarakat yang menempuh pendidikan tinggi memiliki kesiapan yang tinggi pula dalam pengembangan CBT. Hal ini terlihat pada Tabel 4 berikut:

Tabel 4. Kesiapan Masyarakat Terhadap CBT Berdasarkan Tingkat Pendidikan

\begin{tabular}{lccccccc}
\hline \multirow{2}{*}{ Aspek } & \multicolumn{6}{c}{ Mean } & \multicolumn{3}{c}{ ANOVA } \\
& \cline { 2 - 7 } & Tidak & Tamatan & Tamatan & Pendidikan & & \\
& Tamat & SD-SMP & SMA & Tinggi & F Value & P Value \\
\hline Perencanaan & 1.90 & 2,96 & 2,98 & 3,87 & 6,746 & .427 \\
\hline Pengelolaan & 1,83 & 3,45 & 3,51 & 3,96 & 4,014 & .022 \\
\hline Evaluasi & 1,78 & 2,44 & 2,43 & 2,84 & 0,481 & .000 \\
\hline
\end{tabular}

$\mathrm{Df}=4,195 ; \mathrm{F}$ Value $=2.37$ and $\mathrm{p}$ Value $=0.05$

Sumber : Analisis Data, 2018

Berdasarkan kategori umur, jenis kelamin dan pendidikan terlihat bahwa terdapat perbedaan tingkat kesiapan masyarakat lokal Kabupaten Samosir terhadap pengembangan CBT. Tingkat pendidikan dan umur menjadi faktor utama yang mempengaruhi kesiapan masyarakat dalam pengembangan CBT di Kabupaten Samosir. Sementara itu ditinjau dari jenis kelamin, tidak signifikan mempengaruhi kesiapan masyarakat. 
Keberhasilan pariwisata berbasis masyarakat (CBT) sangat ditentukan oleh kesiapan masyarakat untuk terlibat secara langsung. Masyarakat tidak hanya sebagai objek dari pengembangan pariwisata, namun masyarakat juga memiliki peran strategis sebagai penentu arah pembangunan pariwisata. Akan tetapi, selama ini sektor pariwisata hanya mengedepankan aspek profit tanpa membangun masyarakat lokal di sekitar objek wisata. Padahal kehidupan masyarakat juga mempunyai nilai jual pada sektor ini dengan memperkenalkan sejarah dan keragaman budaya misalnya Suku Batak di Kabupaten Samosir, sesuai dengan konsep CBT sebagai pariwisata yang pengelolaan dan pengembangannya dari masyarakat, oleh masyarakat dan untuk masyarakat, mempermudah pengunjung mempelajari masyarakat tersebut dan tata cara hidupnya / local way of life (Murphy dalam Muallisin, 2007)

Tingkat kesiapan masyarakat lokal terhadap pengembangan CBT di Kabupaten Samosir masih rendah pada aspek perencanaan dan evaluasi. Hal ini seharusnya menjadi perhatian dinas pariwisata untuk memberikan kesempatan pada masyarakat terlibat dalam proses perencanaan dan evaluasi pengembangan pariwisata serta dalam pengelolaannya agar masyarakat memperoleh manfaat baik secara ekonomi, budaya (culture), sosial masyarakat dan lingkungan. Hal ini sesuai dengan pernyataan Sunaryo (2013), bahwa prinsip utama dalam CBT yaitu mengikutsertakan anggota masyarakat dalam pengambilan keputusan, manfaat aktivitas kepariwisataan yang diperoleh masyarakat lokal, pendidikan / pelatihan terkait pariwisata bagi masyarakat lokal. Pendidikan kepariwisataan akan dapat meningkatkan kesiapan masyarakat dalam perencanaan, pengelolaan dan evaluasi pengembangan CBT.

\section{KESIMPULAN}

Tingkat kesiapan masyarakat terhadap pengembangan pariwisata berbasis masyarakat (CBT) di Kabupaten Samosir masih rendah pada aspek perencanaan dan evaluasi. Berdasarkan kategori umur, jenis kelamin dan pendidikan terdapat perbedaan tingkat kesiapan masyarakat terhadap pengembangan CBT. Faktor utama yang mempengaruhi tingkat kesiapan masyarakat dalam pengembangan CBT di Kabupaten Samosir yakni pendidikan dan umur. Sementara itu jenis kelamin/gender, tidak secara signifikan mempengaruhi tingkat kesiapan masyarakat. Dalam pengembangan pariwisata berbasis masyarakat (CBT), keterlibatan masyarakat dalam perencanaan, pengelolaan dan evaluasi pengembangan wisata dapat melalui FGD yang diselenggarakan oleh Dinas Pariwisata, Seni dan Budaya Kabupaten Samosir.

\section{UCAPAN TERIMA KASIH}

Terimakasih kepada semua pihak yang terlibat dan ikut memfasilitasi penelitian ini terutama Direktorat Riset dan Pengabdian Masyarakat (DRPM) Pendidikan Tinggi, Rektor Universitas Negeri Medan serta Lembaga Penelitian Universitas Negeri Medan.

\section{DAFTAR RUJUKAN}

Asker, S. A., Boronyak, L. J., Carrard, N. R., \& Paddon, M. (2010). Effective Community Based Tourism: A Best Practice Manual. University of Technology Sydney.

Baryamujura, M., \& Bibangambah, H. K. (2015). A guide on community based tourism.

BPS, K. S. (2016). Samosir Dalam Angka 2016.

Brida, J. G., Disegna, M., \& Osti, L. (2014). Residents' perceptions of tourism impacts and attitudes towards tourism policies. Tourismos, 9(1), 3771.

https://doi.org/10.2139/ssrn.1839244

Delita, F., Yetti, E., \& Sidauruk, T. (2017). Analisis SWOT Untuk Strategi 
Pengembangan Obyek Wisata Pemandian Mual Mata Kecamatan

Pematang Bandar Kabupaten

Simalungun. JURNAL

GEOGRAFI, 9(1), 41-52.

Kementerian Pariwisata. (2015). Laporan.

Laporan Akuntabilitas Kinerja

Kementrian Pariwisata.

Suansri, P. (2003). Community based tourism handbook.

Sunaryo, B. (2013). Kebijakan Pembangunan Destinasi Pariwisata Konsep dan Aplikasinya di Indonesia (Vol. 22).

Zadel, Z., Ivancic, I., \& Cevapovic, I. (2014). RESIDENTS'ATTITUDES TOWARDS TOURISM POTENTIAL OF SMALL RURAL CITY OF POZEGA. In Faculty of Tourism and Hospitality Management in Opatija. Biennial International Congress. Tourism \& Hospitality Industry (p. 174). University of Rijeka, Faculty of Tourism \& Hospitality Management. 